Books, videos, CD-ROMs, DVDs and any

other relavent items submitted for a review

in the $B D J$ should be addressed to: Kate

Maynard, Assistant Editor, British Dental

Journal, NPG, 4-6 Crinan Street, London,

N1 9XW

\section{Oral laser application}

A. Moritz (Ed)
UK: Quintessence
price £178.00, pp 592
ISBN 1850971501

This book is edited by Professor Andreas Moritz, president of the European Society for Oral Laser Applications (ESOLA), who has been involved in the teaching and development of laser dentistry for over 13 years. In fact, all the contributors to the book are experts in the use of lasers and are mostly members of ESOLA.

The stated aim of this textbook is to gather the knowledge of various authors in the use of lasers in dentistry, to help decipher the many concepts and wavelengths available. It is certainly a very well structured, comprehensive book, divided into 13 chapters with excellent illustrations and clinical photographs. Each chapter includes both conventional treatment modalities as well as laser treatment in addition to the underlying disease and its scientific background. The first chapter, 'Basic information on lasers', is set out in such great detail that it requires a graduate of physics to fully understand and appreciate all the information it contains. In addition to that, a unique footnote system is added to nearly every page of the chapter to provide further detail on a more mathematical form or on specific data on the lasers. Coupled with the style of writing, the first chapter was certainly challenging even to an experienced laser clinician.

The book covers all the available laser wavelengths with specific clinical applications and describes in detail the clinical procedure catering for both the complete novice as well as the experienced clinician. Direct comparisons are made between conventional and laser treatments where clinically appropriate and the relevant research is also included. Generally the book is very well referenced and provides a very good atlas for laser users to refer to before embarking on new treatment concepts.

M. A. M. Sulieman

\section{Understanding partial denture design}

\author{
K. Tyson, R. Yemm, B. Scott \\ UK: Oxford University Press \\ price $€ 35.00$, pp 160 \\ ISBN 9780198510925
}

Numerous investigations have shown that the communication of denture design between the surgery and laboratory is often inadequate, with many dentists regularly leaving it to the technician to design the prosthesis. While this new, soft-cover book highlights the essential role of the clinician in the process, it also emphasises the need for a close working relationship. It is aimed at students and newly qualified dentists and endeavours to cover this often poorly understood area in a step-by-step fashion in order to de-mystify the principles underlying good denture design.

Written by clinicians with extensive experience of teaching prosthetics, the book is divided into three sections concentrating on the general principles of partial dentures, assessment of the patient and examples of denture design, and issues surrounding problem solving respectively. In doing this it broadly follows the format of other well known texts, but what sets this book apart is the way the first - and largest - section in particular unlocks difficult concepts with simple and innovative examples. For example, by reference to eggs, suitcase trolleys, ceiling tiles and the Leaning Tower of Pisa, the authors successfully de-mystify concepts associated with undercuts, leverage, clasp positioning and tissue support.

The text is extremely readable and illustrated throughout with excellent, clear line diagrams. However, I feel that more clinical photographs would have been helpful, particularly in the first half of the book.

The remit of the book is denture design and this is triumphantly covered, including the principles behind the surveying of casts. In addition though, I would have liked to have seen more of the clinical and laboratory stages of denture construction covered such as the selection of impression material, impression technique, try-in stages and adjustment, for example.

Not directly covering the clinical stages may prevent this book from becoming a first choice text for some dental schools. However, it remains a very good book and I would recommend it to anyone who wishes to study or revisit the biological and mechanical principles of partial denture design.

D. Barker

\section{The function of teeth}

\section{Gibbs, H.C. Lundeen}

USA: LEG

price $\$ 179+p \& t p$ including DVD,

see www.functionofteeth.com, pp 112 ISBN 0977151107

This book, published by the authors' own publishing company, presents an historical document which ties together the authors' jaw movement research, primarily undertaken in the 1970s and 1980s. The book is divided into six chapters with 200 photographs and diagrams over 112 pages and is written by a prosthodontist and an oral biologist, both eminent leaders in the field of occlusion and temporomandibular joint function. This book is accompanied by a two-hour DVD which is aimed at supplementing the material in the text.

The first chapter provides a comprehensive outline of the experimental instruments and investigations used in the authors' research with respect to recording mandibular movements.

The second chapter presents in detail recordings of the gnathic replicator system during guided and chewing movements of the mandible. This chapter includes a comparison of child and adult chewing patterns and ends with the comparison of chewing patterns of worn and unworn teeth.

The third chapter deals with the experimental investigation of condylar movements using the replicator devised by the research team.

Chapter four exemplifies experiments 

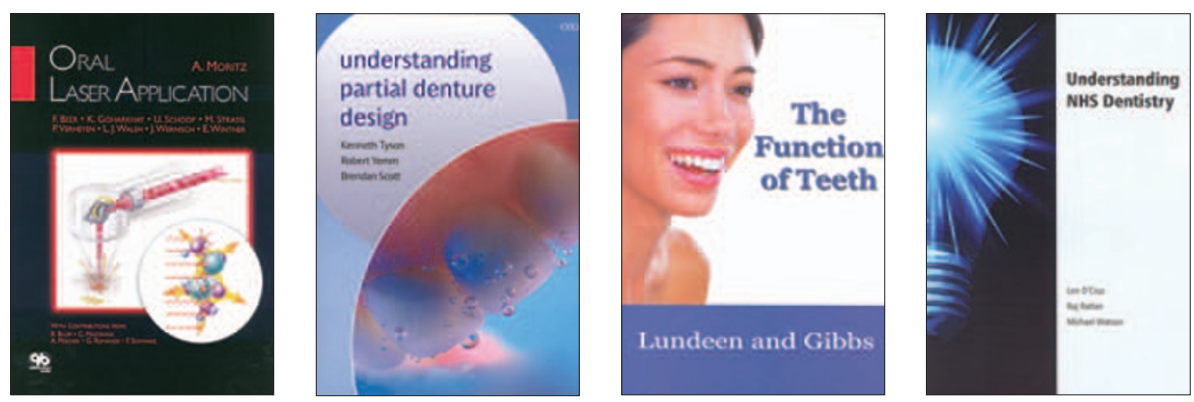

performed to attain pantograph recordings of individuals performing various mandibular movements and their effects.

Chapter five provides an account of the electromyographic studies performed by the research team to investigate the muscular forces generated during mastication and deglutition. The comparison of muscle responses generated during normal occlusion and malocclusion patterns is also covered in this chapter.

The concluding chapter highlights aspects of occlusal anatomy and the importance of occlusal surface reproduction for the attainment of harmonious occlusal and aesthetic results.

Whereas the diagrams in the book are clear and precise and the images on the DVD supplied can be used for lectures and teaching, the experimental methods described in the text and on the DVD are obsolete and lack critical appraisal. This book is clearly not aimed at the general dental practitioner and, in my opinion, benefits only those researchers and clinicians who have an active interest in the detailed study of the physiology of mandibular function related to occlusion.

I. Blum

\section{Understanding NHS dentistry}

\section{D'Cruz, R. Rattan, M. Watson}

UK: New Contract Help

price $€ 30.00$, pp 167

ISBN 0951514539

This book has something for everyone, from the newly qualified associate to practice owners who carry out dentistry within the NHS. Each chapter ends with annexes or points to consider, making the contents relevant and applicable to everyday life. The transition from feeper-item to UDAs and the abandonment of patient registration was a giant leap, and the accompanying rules and regulations require a completely new outlook on the way dentists practise. Local commissioning, for a set amount of work at pre-agreed remuneration, effectively caps dentists' fees. The PCT is now the customer, buying services off the dentists! Without a sound knowledge of these basic issues the working dentist or practice owner cannot make the most of the new contract.

Who can have a contract, and which type; practices of individual dentists? Which patients will you see, your regular ones or anyone that requests treatment? What services will you offer and which sort of treatment are you allowed to carry out. Will you provide specialist services? Do patients need to be dentally fit? Along with models for building protocols and guidelines for terminating and phasing treatment, these issues are covered.

Aside from the clinical aspect of dentistry, the importance of performance management, with particular reference to the use of IT, is emphasised. Explaining how contract values are calculated and the possible entitlement to maternity/ paternity and long-term sick leave payments are examined. Complaints affect everyone in their practising lives. This publication provides an insight into the processes, including the bodies involved and possible outcomes.

The subjects of whether associates are, and will continue to be, self-employed and the implications of this for practice owners are raised. Payment models and associate contracts are issues that will affect many dentists; with the prospect of increasing numbers of more commercially minded corporate bodies, associates may wish to know this topic in more detail.

The ever-present issues of quality and clinical governance will not disappear, and may become more important in years to come. These, along with business considerations of running practices, are addressed in some detail.

The final chapters cover strategies to manage future change and how NHS dentistry may develop.

This book should be read by all that have interest in NHS dentistry. It should then be kept for reference as, with so much information included, continued reminders will be necessary.

D. Flanagan 